\title{
Interleukin- 6 is required for cell cycle arrest and activation of DNA repair enzymes after partial hepatectomy in mice
}

Shingo Tachibana ${ }^{1,2+}$, Xiuying Zhang ${ }^{1,3+}$, Kazushige Ito ${ }^{1,2+}$, Yoshihiro Ota ${ }^{1}$, Andrew M Cameron', George Melville Williams ${ }^{1}$ and Zhaoli Sun ${ }^{1 *}$

\begin{abstract}
Background: Interleukin-6 (IL-6) has been shown to be vital for liver regeneration, however the specific mechanisms and factors involved remain incompletely defined. The present study aimed to investigate whether IL-6 exerts its protective effects via arresting the cell cycle allowing base excision and repair of oxidized DNA after hepatectomy.

Results: Following seventy percent partial hepatectomy (PH) in wild type (WT) mice IL-6 serum levels increased reaching peak levels at 3 hours. This was associated with markers of cell cycle arrest as p21 expression was increased and cyclin D1 and proliferating cell nuclear antigen (PCNA) expression decreased. In the absence of IL-6, markers of cell cycle arrest were absent and the number of bromodeoxyuridine (BrdU) positive cells was significantly higher at 28, 32 and 36 hours after PH. The mRNAs for DNA repair enzymes, including Neil-1, 8-oxodGTPase, OGG1, Apex1, and UDG (DNA glycosylase) were increased 2 to 4 fold in WT mice at 6 and/or 12 hours after PH compared to IL-6 knockout (KO) mice. The protein levels of Neil1 and OGG1 were also significantly increased in WT mice compared to KO mice. Pathological changes were far greater and survival was less in IL-6 KO mice than in WT mice. Administration of IL-6 in KO mice restored p21 and DNA repair enzyme expression to wild-type levels and survival was improved.
\end{abstract}

Conclusions: IL-6 caused cell cycle arrest and delayed proliferation during the first day after PH. This delay was associated with the activation of DNA repair enzymes resulting in accurate replication and restoration of hepatic mass.

Keywords: IL-6, Cell cycle arrest, Oxidative DNA damage and repair, Partial hepatectomy, Liver regeneration, Mice

\section{Background}

Liver regeneration in response to partial resection is an efficient and precisely regulated process during which the surviving liver cells proliferate to reconstitute the liver. In rats, the two third partial hepatectomy $(\sim 70 \% \mathrm{PH})$ induces a compensatory hyperplasia of the remaining lobes that restores the original liver mass within 7 to 10 days [1]. Resection of half of the human liver is followed within 2-4 weeks by full restoration of the liver structure, size, and function [2,3]. However, even in patients without pre-

\footnotetext{
* Correspondence: zlsun@jhmi.edu

${ }^{\dagger}$ Equal contributors

'Department of Surgery, Johns Hopkins University School of Medicine, 720

Rutland Ave., Ross 771, Baltimore, MD 21205, USA

Full list of author information is available at the end of the article
}

existing liver disease, more significant liver resections, i.e. greater than $75 \%$, result in an increasing perioperative mortality [4].

Interleukin (IL)-6 is a pleiotropic cytokine, which has been shown to provide liver protection in various settings [5-10]. Liver regeneration is impaired in $I L-6$ knockout mice [11], while IL-6 overexpression is involved in delayed liver regeneration [12]. While IL-6 has been shown to be vital for liver regeneration $[6,13,14]$, the specific mechanisms and factors involved remain incompletely defined. Identifying the molecular signals that promote regeneration may well lead to therapies that would aid recovery from massive liver injury or surgery.

\section{Ciomed Central}

(c) 2014 Tachibana et al.; licensee BioMed Central Ltd. This is an Open Access article distributed under the terms of the Creative Commons Attribution License (http://creativecommons.org/licenses/by/2.0), which permits unrestricted use, distribution, and reproduction in any medium, provided the original work is properly credited. The Creative Commons Public Domain Dedication waiver (http://creativecommons.org/publicdomain/zero/1.0/) applies to the data made available in this article, unless otherwise stated. 
Over stimulation of TNF- $\alpha$ and increased sensitivity to endotoxin (lipopolysacharides) have been proposed [15] as possible mechanisms for the intracellular production of ROS and lipid peroxidation known to follow 70\% $\mathrm{PH}$. While low amounts of ROS may play important roles in liver regeneration after $\mathrm{PH}$, excessive amounts of reactive oxygen species (ROS) are likely to damage cellular DNA. The oxidative injury is more dramatic after large (87\%) hepatectomy [14]. Accordingly, we reasoned if the DNA is significantly oxidized and mutated, stringent, robust repair mechanisms would be required to enable injured hepatocytes to proliferate efficiently. We hypothesized that IL-6 exerts its protective effects via arresting the cell cycle allowing base excision and repair of oxidized DNA after hepatectomy.

\section{Results}

\section{IL-6 Is Important for Survival after 70\% PH in Mice}

We performed 70\% PH in WT mice, in IL-6 KO mice, and in IL- $6 \mathrm{KO}$ mice that were treated 30 minutes before surgery with subcutaneous (SC) injections of recombinant IL-6. Some mice were followed to determine survival rates while others were sacrificed at $0,3,6,9$, $12,24,32,48$ and 72 hours after partial hepatectomy. The serum level of IL- 6 increased dramatically in WT mice, reaching peak levels at 3 hours and remained at a high level at $24 \mathrm{~h}$ after PH. No IL-6 was detected in IL-6 KO mice (Figure 1A). IL-6 stimulation was associated with increases in phosphorylated-Stat3 (p-Stat3) in the liver of WT mice compared to IL-6 KO mice (Figure 1B). Animal survival at 7 days after PH was $100 \%$ for WT mice and $17 \%$ for IL-6 KO mice. SC injection of IL-6 in $\mathrm{KO}$ mice resulted in survival of $67 \%$ (Figure 1C).

Increased oxidative DNA damage in IL-6 KO Mice after PH There was no gross morphological difference between WT and IL-6 KO mice on days 1 and 2 (Figure 2A). IL-6 KO livers (middle panel) looked larger than the WT on day 2 after PH. However, on day 3, livers from the mice without IL-6 had a pale-yellowish color and the liver size did not increase further. In contrast, the WT liver increased in size and had a normal color. $\mathrm{H}$ and $\mathrm{E}$ staining demonstrated that necrosis appeared in liver tissue sections recovered from IL-6 KO mice at 48 hours after PH (Figure 2B), and this progressed to massive areas of necrosis at 72 hours. These features were absent in liver sections from WT mice after PH.

Using a competitive ELISA method, levels of 8-OHdG in total DNA were determined after $\mathrm{PH}$ and were found significantly and equally elevated in the DNA of the livers from both WT and IL-6 KO mice at 24 hours (Figure 2C). Interestingly, 8-OHdG levels in the DNA from WT mice decreased significantly at 48 hours after $\mathrm{PH}$, whereas 8 -OHdG levels from $\mathrm{KO}$ mice remained significantly elevated.

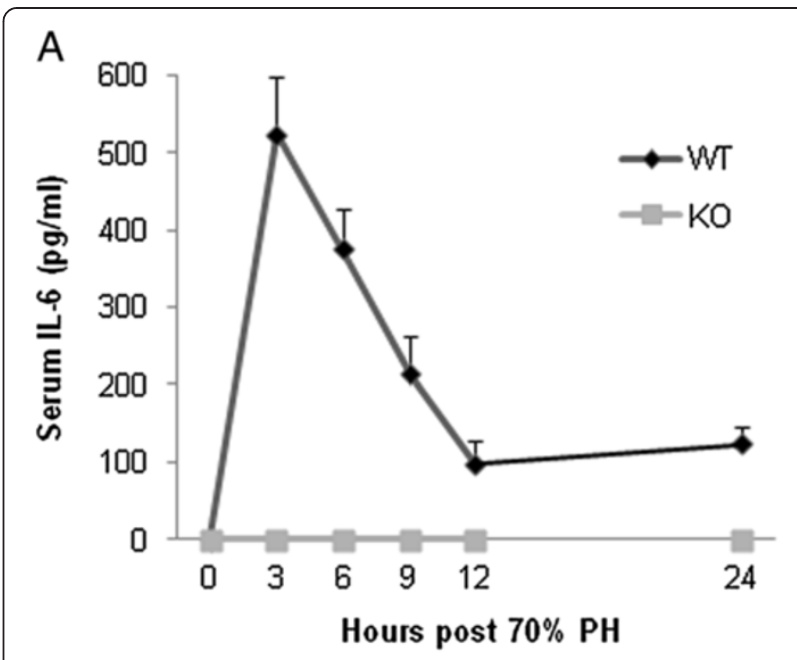

B
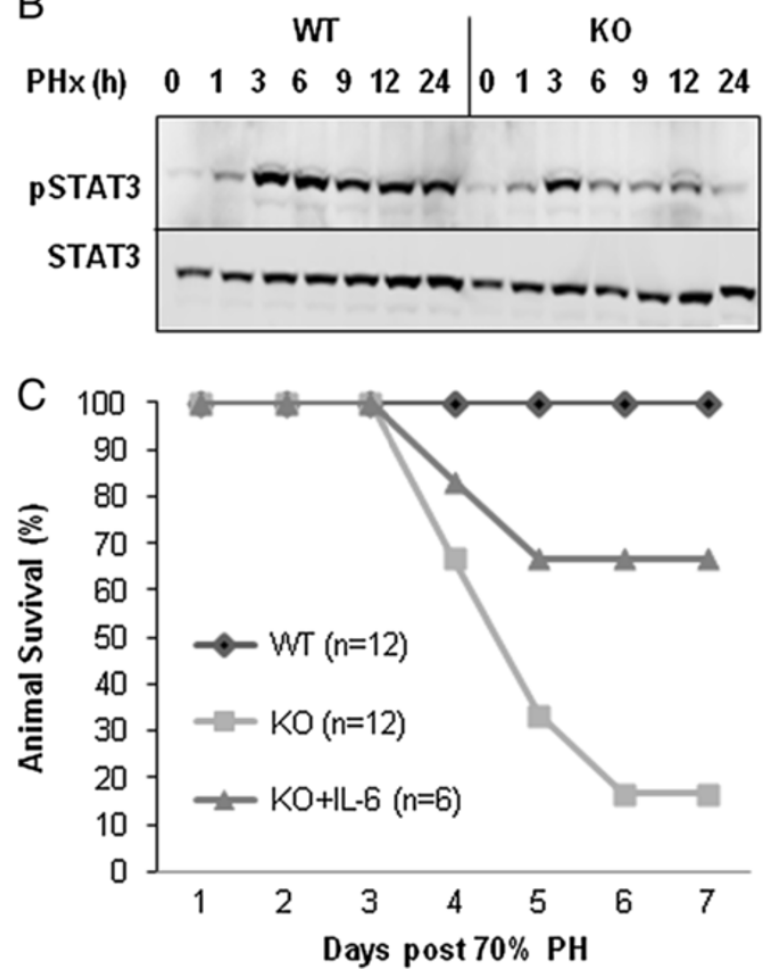

Figure 1 IL- 6 production, Stat 3 activation and mortality after $\mathrm{PH}$. Eight to 10 week-old male IL-6 KO or WT mice were subject to $70 \%$ PH and then observed for 7 days or sacrificed at different time points.

(A) Serum IL-6 levels were measured by ELISA. (B) Phosphorylated-Stat3 ( $p$-Stat3) was measured by western blot. P-Stat3 expression was significantly increased in the liver of WT mice compared to IL-6 KO mice. (C) Animal survival during the 7 days after $70 \% \mathrm{PH}$ was $100 \%$ for WT mice and 17\% for IL-6 KO mice. SC injection of IL-6 in KO mice resulted in survival of $67 \%$.

IL-6 Regulates cell cycle at early time after partial hepatectomy

Using western blot analysis, we found that cyclin-D1 expression was increased as early as 3 hours and remained 


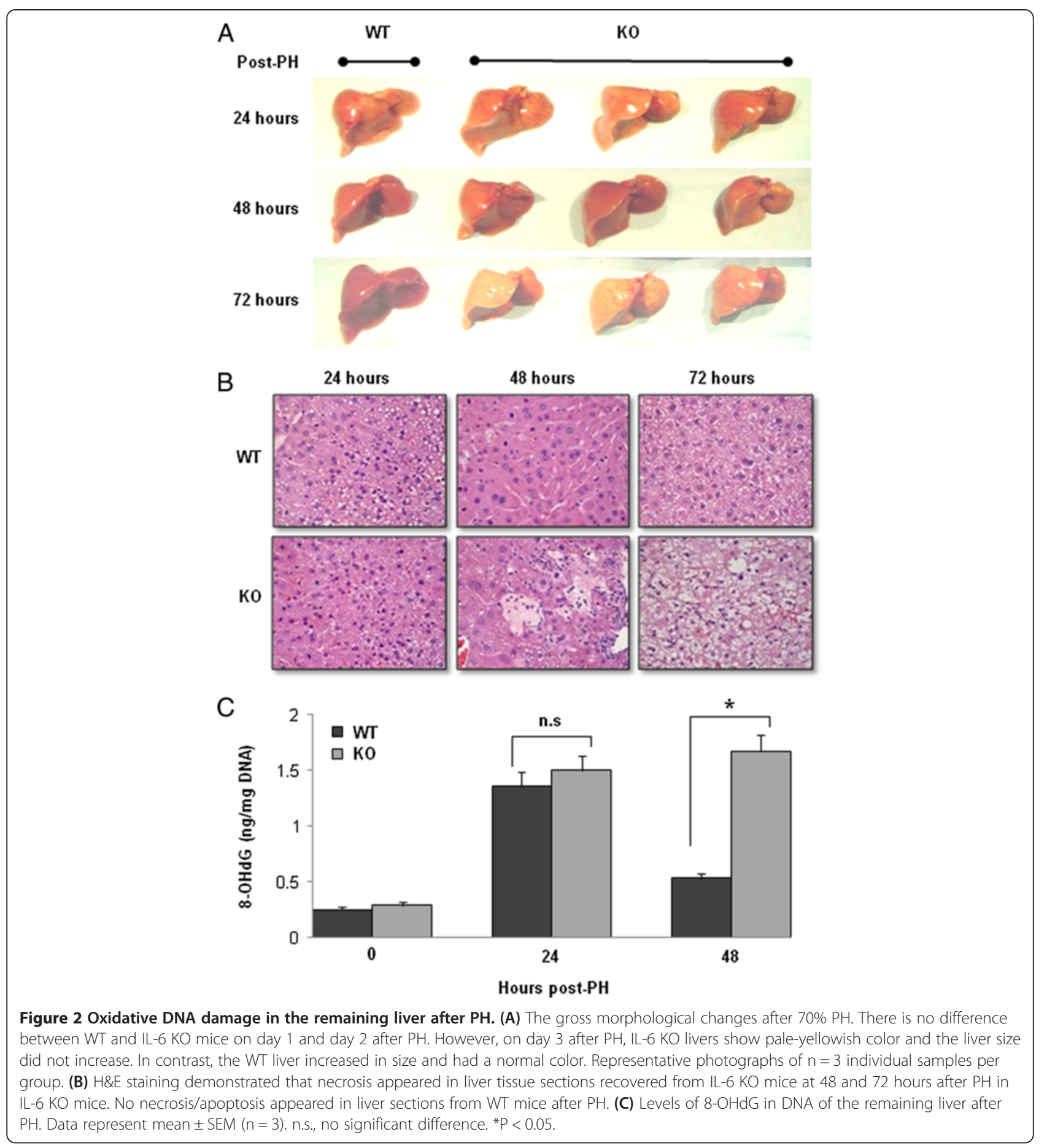

at the higher levels in the IL-6 KO mice after 70\% $\mathrm{PH}$ (Figure 3). In contrast, there was no increase of cyclinD1 in WT mice until 24 hour after 70\% PH. Proliferating cell nuclear antigen (PCNA) expression was also significantly increased in IL-6 KO mice at 24 hours after PH while similar to cyclin D-1 there was no increase of PCNA in WT mice. Interestingly, the expression of cell cycle inhibitor, p21, was significantly higher in WT mice at 6 and 24 hours after PH compared to IL- 6 KO mice which had minimal if any p21 expression. Figure 3 shows that full length PARP expression was decreased in IL-6 KO mice compared to WT mice at 6, 12, and 24 hours after $\mathrm{PH}$.

Immunohistochemistry staining detecting the p21 and PCNA proteins supported the findings above. There were more p21 positive hepatocytes in the liver tissue 


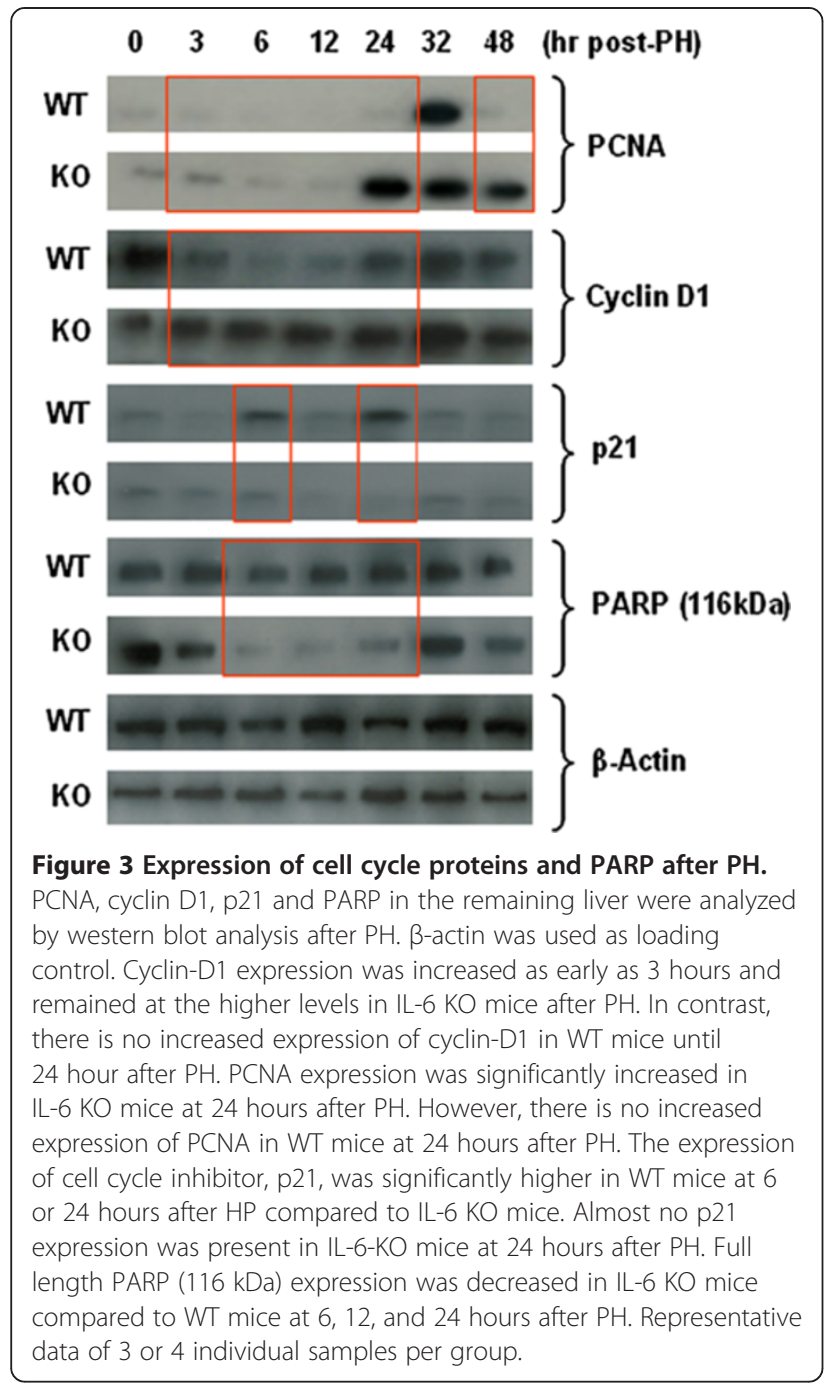

sections from WT mice compared to $\mathrm{KO}$ mice at 6 and 24 hours after $\mathrm{PH}$ (Figure 4A). In contrast, there were fewer PCNA positive cells in the liver tissue sections from WT mice compared to KO mice at 24 hours after $\mathrm{PH}$ (Figure 4B). The suggestion that acute cell cycle arrest occurred in WT mice was confirmed by BrdU incorporation assays. There was no increase in the number of BrdU positive cells ( $\mathrm{S}$ phase) in liver tissue sections from WT mice until 32 hours after PH (Figure 5). However, the number of BrdU positive hepatocytes in liver tissue sections from $\mathrm{KO}$ mice was significantly increased as early as 28 hours after $\mathrm{PH}$ and the number of BrdU positive cells was significant higher in $\mathrm{KO}$ mice compared to WT mice at 32 or 36 hours after $\mathrm{PH}$. The data indicate that in the presence of IL-6, replication was stimulated in cells hampered by oxidized DNA.

Activation of DNA repair enzymes occurred in WT mice but not in IL-6 KO mice after 70\% PH, and IL-6 pretreatment restored cell cycle arrest and increased DNA repair enzymes.
We measured the mRNA of several DNA repair enzymes in order to assess whether cell cycle arrest was associated with their upregulation. Using quantitative-real time PCR, the mRNA expression of PARP, UDG and Apex was significantly increased in WT mice compared to $\mathrm{KO}$ mice at 6 hours after $70 \% \mathrm{H}$, while that of Neill, OGG1 and 8-oxo-GTP was significantly increased in WT mice compared to KO mice at 12 hours after $70 \%$ PH (Figure 6). Neil1 and OGG1 protein levels were also studied by immunohistochemistry and western blot analyses. As shown in Figure 7, the number of Neill or OGG1 positive hepatocytes was significantly increased in WT mice or KO mice pretreated with IL-6 compared to $\mathrm{KO}$ mice after $7 \% \mathrm{H}$ (Figure $7 \mathrm{~A}$ and $\mathrm{B}$ ). Western blot analysis confirmed the finding that expression of p21, Neil1 and OGG1 was increased only in WT mice or IL-6 KO mice with SC injection of IL-6 (Figure 7C).

\section{Discussion}

The expected burst of IL-6 secretion was present after $70 \% \mathrm{PH}$, but instead of finding robust measures of early proliferation we found depressed BrdU incorporation and evidence of cell cycle arrest as p21 expression was increased and cyclin-D1 and PCNA expression was depressed. IL-6 KO mice had the reverse pattern with greater early incorporation of BrdU, absent p21 and increased cyclin-D1 and PCNA levels. To explain this seeming paradox where normal mice had evidence of cellular slow down and the IL-6 deficient mice were geared to replicate, we proposed that cell cycle arrest was needed to create a check point to allow for activation of DNA repair enzymes and to have them excise and replace oxidized DNA thereby permitting accurate replication.

Using measurements of the stable oxidized adduct 8OHdG as an indication of DNA oxidative injury, we confirmed that significant oxidative injury occurred equally in both IL-6 KO and WT mice at 24 hours after $\mathrm{PH}$. However, by day two there was little 8 -OHdG in the WT mice and much more in the IL-6 KO mice. This was associated with striking differences in histology as the WT mice displayed normal histology while the IL-6 KO mice had extensive areas of necrosis. The best explanation for this difference is that the absence of a check point in the IL-6 KO mice resulted in rapid but faulty DNA replication leading to apoptosis/necrosis.

The mechanism leading to cell cycle arrest is likely related to the increased expression of p21 found in the WT mice at 6 and 24 hours after 70\% $\mathrm{PH}$ compared to IL-6 KO mice. We have shown in previous studies [16-19] that IL-6 significantly increased phosphorylated STAT3, which stimulated p21 transcription [20-23] resulting in G-1 arrest. We propose that normal mice had sufficiently high levels of IL-6 after 70\% PH to increase p21 production via activated STAT3 thereby 


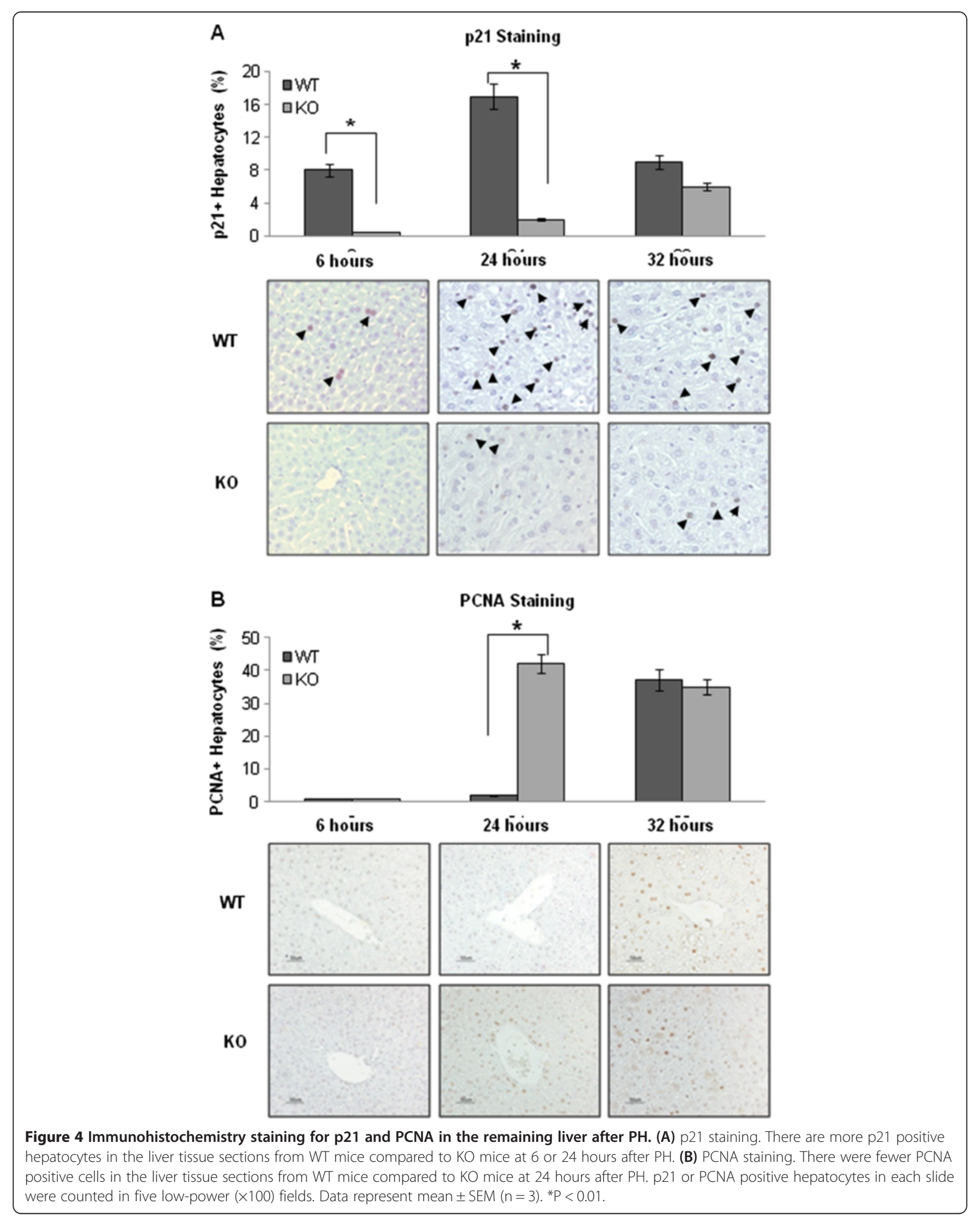




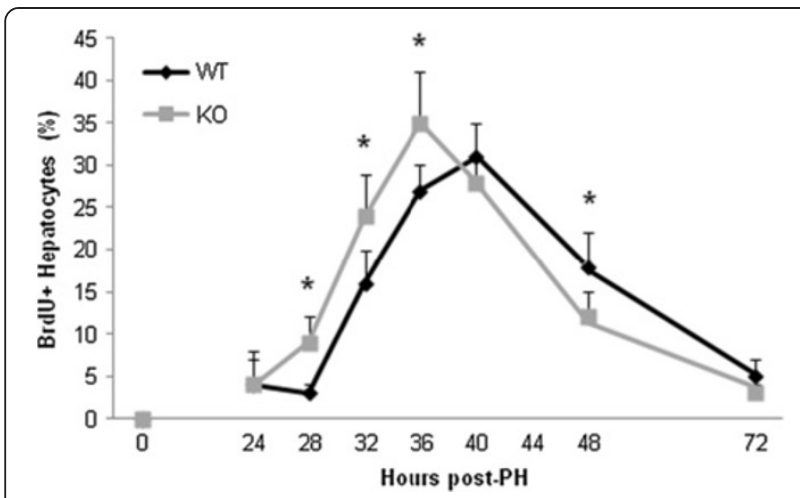

Figure 5 Hepatocyte proliferation in vivo was determined using the bromodeoxyuridine (BrdU) incorporation assay. Mice were injected (IP) with BrdU (50 $\mathrm{mg} / \mathrm{g}$ body weight) and euthanized 2 hours later, and the livers were harvested for $\mathrm{IHC}$ staining of BrdU using a kit (BD Biosciences). The percentage of BrdU-labeled hepatocytes in each slide was counted in five low-power $(\times 100)$ fields. Data represent mean $\pm \operatorname{SEM}(n=3)$. * $P<0.05$.

leading to cyclin D-1 and PCNA expression and to G-1/S arrest. This hypothesis is supported by the finding that rIL-6 stabilized steatotic hepatocytes from obese animals by normalizing PCNA expression (G1 phase) and not by increasing DNA synthesis (BrdU, S phase) [24].

We have found that the expression of p21 was significantly higher in WT mice at 6 and 24 hours, but not 12 hours after PH compared to IL-6 KO mice which had minimal if any p21 expression. Interestingly, the expression of p21 was increased only at 6 and 24 hours in IL-6 KO mice with SC injection of IL-6. It has been reported that two waves of STAT3 activation were observed after $\mathrm{PH}$, the first in endothelia and the second in hepatocytes, and STAT3 activation was positively correlated with p21 protein expression [25]. Two peaks of p21 expression at early time after $\mathrm{PH}$ might be due to IL-6 dependent activation of STAT3.

Direct evidence supporting the key role of DNA repair comes from the finding that the principle known enzymes for DNA repair, OGG-1, 8-oxo-GTP, Neil-1 were stimulated in the WT mice but absent in the IL-6 KO mice following 70\% PH. PARP which repairs single strand breaks most commonly caused by per oxidation was also found increased at early time points in WT mice. The crucial role of IL-6 is supported by the restoration of early cell cycle arrest in IL-6 KO mice and subsequent benefit by a single injection 30 minutes before $70 \% \mathrm{PH}$.

Other studies have also linked IL-6 with DNA repair. Efferth et al. [26] reported that IL-6 improved DNA repair in melphalan-induced DNA damaged human multiple myeloma cells. Other reports have shown that IL-6 mRNA is stimulated after DNA strand breaks [27] and persistent DNA damage triggers senescence-associated inflammatory cytokine secretion including IL-6 [28,29]. We have shown that activation of DNA repair enzymes occurred in WT mice and could be restored in IL-6 KO mice by IL-6 injection just before $70 \% \mathrm{PH}$.

In conclusion, we provide evidence that the essential role of IL-6 in liver regeneration after 70\% $\mathrm{PH}$ is the induction of cell cycle checkpoints and activation of DNA repair enzymes in the remaining liver. IL-6 promoted DNA repair, but was not a requirement for liver cell proliferation. Cell cycle arrest permitted time for the transcription of DNA repair enzymes, DNA base excision repair and subsequent accurate cellular replication.

\section{Materials and methods}

\section{Animals and partial hepatectomy}

Male C57BL/6 J background IL-6 KO mice and control C57BL/6 J (WT) mice weighing 20-25 g were purchased from the Jackson Laboratory (Bar Harbor, ME). Animals were maintained in a pathogen-free facility of The Johns Hopkins Medical Institutions. Animals were cared for according to $\mathrm{NIH}$ guidelines and under a protocol approved by the Johns Hopkins University Animal Care Committee. For the IL-6-injected group, IL-6 KO mice were given a subcutaneous injection with recombinant IL-6 at a dose of $500 \mathrm{ng} / \mathrm{g}$ of animal weight thirty minutes before hepatectomy. Animals were anesthetized with isofluorane. After a midline laparotomy, the left and middle lobes $(\sim 70 \%)$ of the liver were ligated at the base and removed. The abdominal wall and skin were sutured separately. After surgery, animals were immediately given free access to water. Following surgery, mice were sacrificed, and livers and caval blood samples were collected at predetermined time points after operation. Harvested livers were weighted to assess regeneration, and portions of liver tissue were either fixed in $10 \%$ neutralized formalin for histological evaluation or were snap frozen in liquid nitrogen and maintained at $-80^{\circ} \mathrm{C}$ until homogenization for various biochemical assays. For assessment of hepatic proliferation, BrdU was injected (50 mg/kg intraperitoneal (IP)) 2 hours prior to harvesting of liver.

\section{Analysis of alanine aminotransaminase and aspartate aminotransaminase activity}

Acute liver injury was quantified by measurement of serum alanine aminotransaminase (ALT) and aspartate aminotransaminase (AST) levels using an automated enzyme assay.

\section{Histopathological analysis}

Cut sections of $4 \mu \mathrm{m}$ were prepared from formalin-fixed paraffin-embedded tissues for immunohistochemistry. Each representative section was stained with hematoxylin-eosin (H\&E). Immunohistochemical staining was performed with 


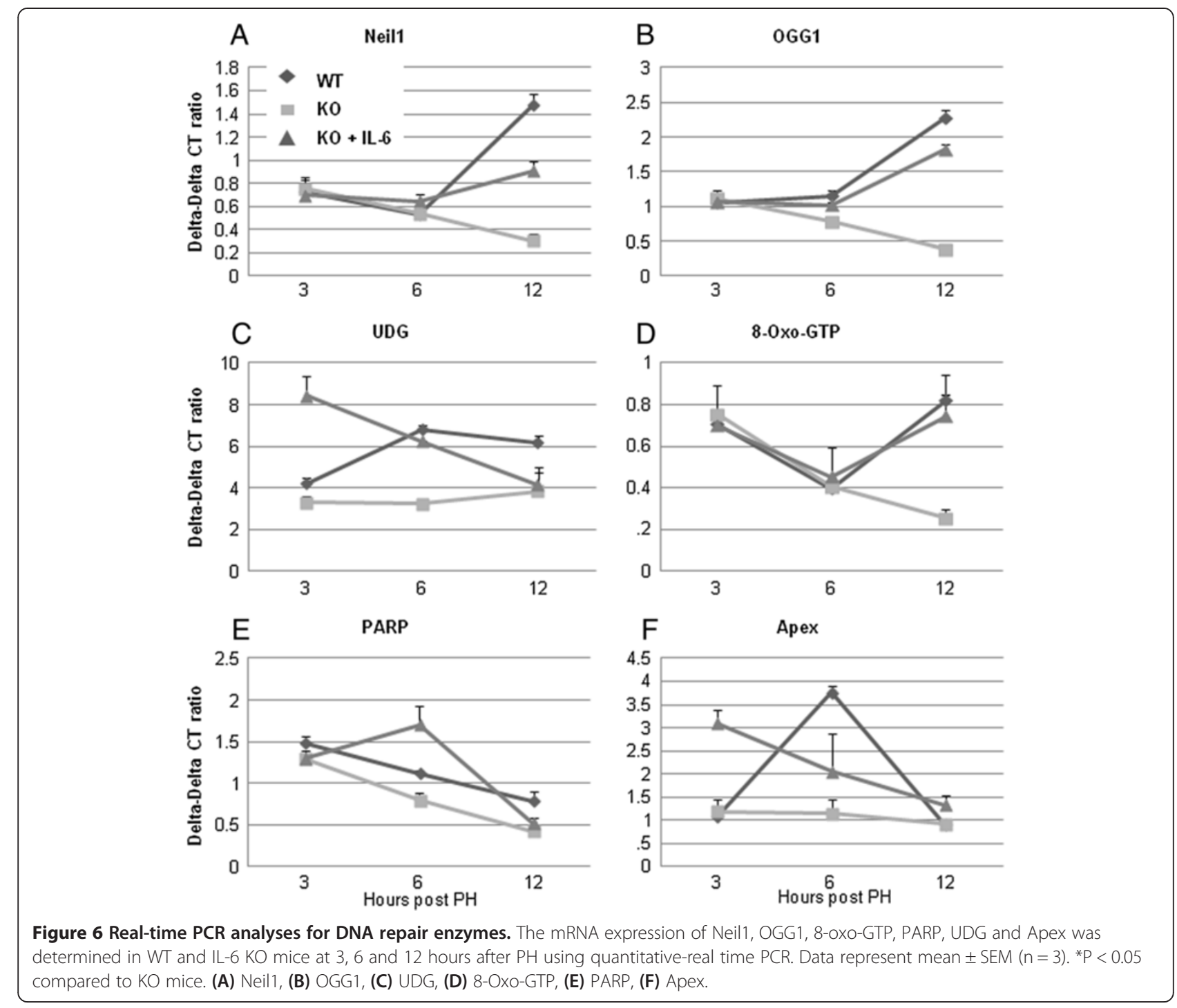

the avidin-biotin-peroxidase complex method, using Vectastain ABC kits (Vector Laboratories, Burlingame, $\mathrm{CA})$ according to the methods described before $[19,28,30]$. The following antibodies were used: mouse anti-BrdU 1 monoclonal antibody (Molecular Probes) (1:200); antiPCNA antibody (Cell Signaling) (1: 5000); polyclonal antiOGG1 antibody (1:100) (Novus Biological, Littleton, CO); monoclonal anti-p21 antibody (1:200) and polyclonal anti-Neil1 antibody (1:100) (Cell Signaling Technology, Boston, MA). The antibodies were incubated either at $4^{\circ} \mathrm{C}$ overnight or at room temperature for 1.5 hours. Immunohistochemistry staining of bromodeoxyuridine (BrdU) was performed by using a BrdU incorporation assay kit (BD Biosciences).

ELISA assay for measurement of 8-OHdG Levels in DNA The DNA was extracted using the DNeasy tissue kit (Qiagen, Santa Clara, CA) according to the manufacturer's instruction [28]. The levels of $8-\mathrm{OHdG}$ in nucleoside samples were used for the determination of 8-OHdG by a competitive ELISA kit (8-OHdG Check, Institute for the Control of Aging). The determination range was $0.125-10 \mathrm{ng} / \mathrm{ml}$ or $0.5-200 \mathrm{ng} / \mathrm{ml}$. The levels of 8-OHdG were expressed as amounts of 8-OHdG (ng) per milligram of DNA.

\section{Western blot analysis}

Tissues were homogenized in lysis buffer $(30 \mathrm{mmol} / \mathrm{L}$ Tris, $\mathrm{pH}$ 7.5, $150 \mathrm{mmol} / \mathrm{L}$ sodium chloride, $1 \mathrm{mmol} / \mathrm{L}$ phenylmethylsulfonyl fluoride, $1 \mathrm{mmol} / \mathrm{L}$ sodium orthovanadate, $1 \%$ Nonidet P- $40,10 \%$ glycerol) at $4{ }^{\circ} \mathrm{C}$, vortexed and centrifuged at $16,000 \mathrm{rpm}$ at $4^{\circ} \mathrm{C}$ for 10 minutes. The supernatants were mixed in SDS sample loading buffer (NuPAGE, Invitrogen), $70^{\circ} \mathrm{C}$ for 10 minutes, and then subjected to SDS-PAGE. After electrophoresis, proteins were transferred onto PVDF membranes and blotted against 


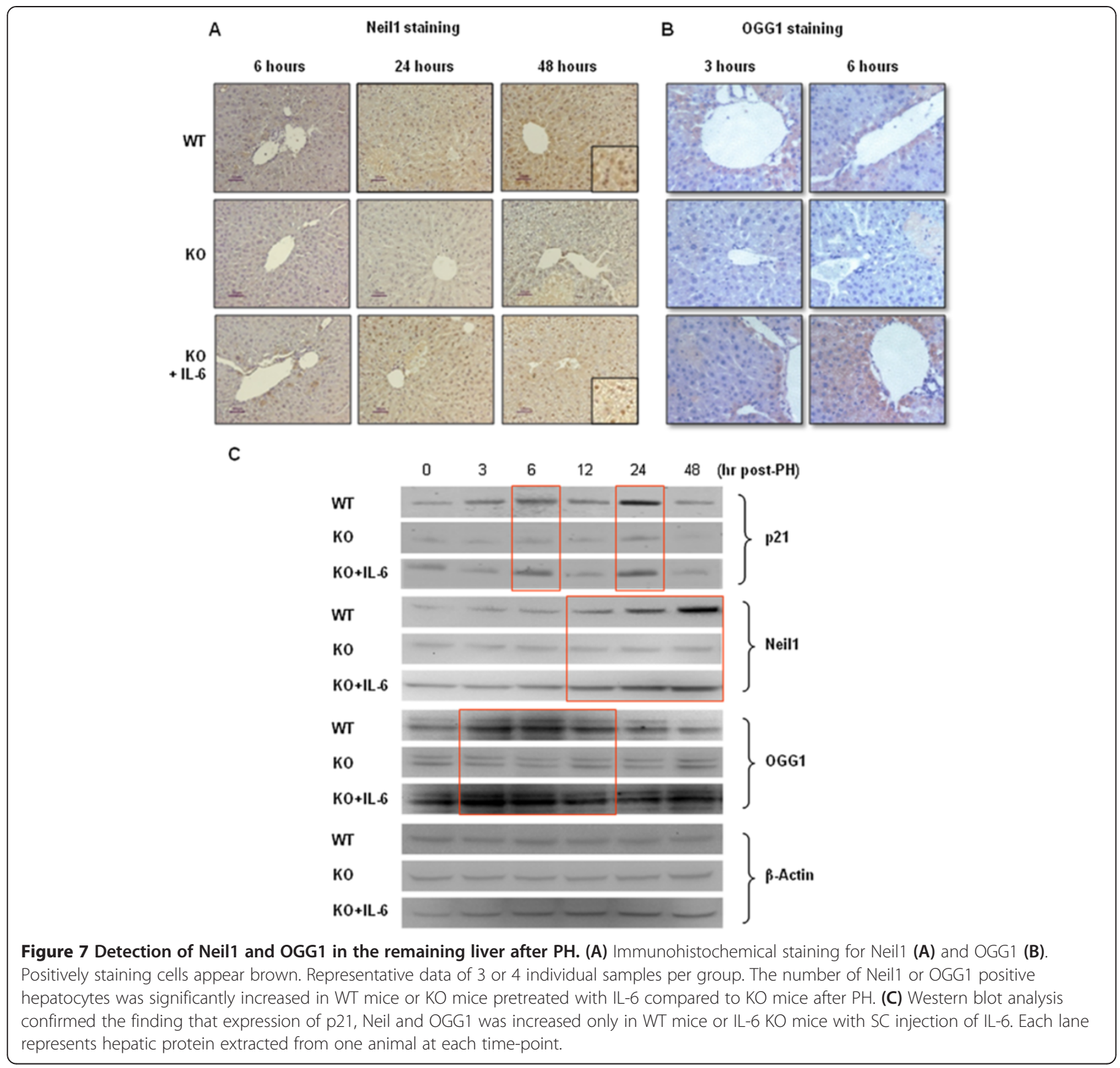

primary antibodies (anti-p21 (1:2000), anti-Neil1 (1:1000), anti-OGG1 (1:1000), anti-PARP (1:1000, \#9542, Cell Signaling Technology) and anti- $\beta$-actin (1:1000)) for 1 hour at room temperature. Membranes were washed with TPBS $(0.05 \%$ [vol/vol] Tween 20 in phosphatebuffered saline [pH 7.4]) and incubated with a 1:4000 dilution of horseradish peroxidase-conjugated secondary antibodies for 45 minutes. Protein bands were visualized by an enhanced chemiluminescence reaction (ECL-plus, Bio-Rad).

Real-Time PCR Analysis for DNA repair enzyme mRNA The primer sets for amplification of mouse Neil1 were 5'-ACCCTGTGTCTTGCTGGAGT-3' and 5'-TGCAGG
GCCTCTAGAACTGT-3'. The primer sets for amplification of mouse OGG1 were 5'-GACTACGGCTGGCAT CCTAAG-3' and 5'-GCAAAAAGGGATCTAAGAGGC-3'. The primer sets for control amplification of glyceraldehyde 3-phosphate dehydrogenase (GAPDH) were 5'ATTCAACGGCACAGTCAAGG-3' and 5'- CACACC CATCACAAACATGG-3'. For the Real-Time PCR procedure: The cDNA was diluted 1:10 and $2 \mu \mathrm{l}$ were used as template in a $25 \mu \mathrm{l}$ qPCR reaction. The qPCR assays were performed as described previously, using SYBR Green (Applied Biosystems, Foster City, CA) on the IQ5(Bio-Rad). Amplification conditions were $95^{\circ} \mathrm{C}$ for 5 minutes and cycles of $95^{\circ} \mathrm{C}$ for 30 seconds, $59^{\circ} \mathrm{C}$ for 30 seconds, and $72^{\circ} \mathrm{C}$ for 30 minute, with a final 
extension at $72^{\circ} \mathrm{C}$ for 5 minutes. All PCR reactions were performed in triplicate. After amplification, we determined the threshold cycle $(\mathrm{Ct})$ to obtain expression values of $2^{-\mathrm{Ct}}$, as described previously. A $\Delta \mathrm{CT}$ value was first calculated by subtracting the $\mathrm{CT}$ value for the housekeeping gene GAPDH from the CT value for each sample. A $\Delta \Delta C T$ value was then calculated by subtracting the $\Delta \mathrm{CT}$ value of the control (normal control) from the $\Delta \mathrm{CT}$ value of each treatment.

\section{Statistics}

The results were expressed as mean values \pm SEM of $n$ independent experiments. Analyses were performed using the paired Student $t$ test and the analysis of variance (ANOVA) with repeated measures. $P$ values less than .05 was considered a significant difference between $\mathrm{KO}$ mice and WT mice.

\begin{abstract}
Abbreviation
Apex: DNA-(apurinic or apyrimidinic site) lyase; BrdU: Bromodeoxyuridine; IL-6: Interleukin-6; KO: Knock out; Neil1: Nei endonuclease VIII-like 1; OGG1: 8-Oxoguanine glycosylase; 8-OHdG: 8-hydroxy-2' -deoxyguanosine; 8-oxo-GTP: 8-oxoguanine derivative of GTP; PARP: Poly ADP ribose polymerase; PCNA: Proliferating cell nuclear antigen; PH: Partial hepatectomy; p-Stat3: phosphorylated-Stat3; p21: CDK-interacting protein 1; ROS: Reactive oxygen species; SC: Subcutaneous; UDG: Uracil-DNA glycosylase; WT: Wild type.
\end{abstract}

\section{Competing interests}

The authors declare that they have no competing interests. The authors alone are responsible for the content and writing of the paper.

\section{Authors' contributions}

ST, XZ and KI performed majority of the experiments, analyzed data and prepared the manuscript. Specifically, ST and KI performed PH and western blot analysis, XZ performed histological analysis, ELISA and PCR. AMC and GMW provided suggestions for the project and edited the manuscript. ZS designed the overall study, supervised the project, and wrote the manuscript. All authors read and approved the final manuscript.

\section{Author details}

${ }^{1}$ Department of Surgery, Johns Hopkins University School of Medicine, 720 Rutland Ave., Ross 771, Baltimore, MD 21205, USA. '2Department of Surgery, Tokyo Medical University, Shinjuku, Tokyo, Japan. ${ }^{3}$ School of Life Science, Tianjin University, Tianjin, China.

Received: 15 October 2013 Accepted: 5 November 2013 Published: 3 February 2014

\section{References}

1. Michalopoulos GK, DeFrances MC: Liver regeneration. Science 1997, 276:60-66.

2. Fausto N, Campbell JS, Riehle KJ: Liver regeneration. Hepatology 2006, 43(Suppl):S45-S53

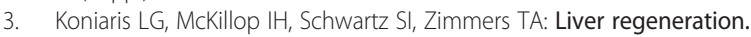
J Am Coll Surg 2003, 197:634-659.

4. Vauthey JN, Zorzi D, Pawlik TM: Making unresectable hepatic colorectal metastases resectable- does it work? Semin Oncol 2005, 32:S118-S122.

5. Galun E, Zeira E, Pappo O, Peters M, Rose-John S: Liver regeneration induced by a designer human IL-6/sIL-6R fusion protein reverses severe hepatocellular injury. Faseb J 2000, 14:1979-1987.

6. Aldeguer X, Debonera F, Shaked A, Krasinkas AM, Gelman AE, et al: Interleukin- 6 from intrahepatic cells of bone marrow origin is required for normal murine liver regeneration. Hepatology 2002, 35:40-48.
7. Kovalovich K, DeAngelis RA, Li W, Furth EE, Ciliberto G, et al: Increased toxin-induced liver injury and fibrosis in interleukin-6-deficient mice. Hepatology 2000, 31:149-159.

8. Kovalovich K, Li W, DeAngelis R, Greenbaum LE, Ciliberto G, et al: Interleukin-6 protects against Fas-mediated death by establishing a critical level of anti-apoptotic hepatic proteins FLIP, Bcl-2, and Bcl-xL. J Biol Chem 2001, 276:26605-26613.

9. Sun R, Jaruga B, Kulkarni S, Sun H, Gao B: IL-6 modulates hepatocyte proliferation via induction of HGF/p21cip1: regulation by SOCS3. Biochem Biophys Res Commun 2005, 338(4):1943-1949.

10. Gao B: Hepatoprotective and anti-inflammatory cytokines in alcoholic liver disease. J Gastroenterol Hepatol 2012, 27(Suppl 2):89-93.

11. Cressman DE, Greenbaum LE, DeAngelis RA, Ciliberto G, Furth EE, Poli V, Taub R: Liver failure and defective hepatocyte regeneration in interleukin-6-deficient mice. Science 1996, 274(5291):1379-1383.

12. Quétier I, Brezillon N, Duriez M, Massinet H, Giang E, Ahodantin J, Lamant C, Brunelle MN, Soussan P, Kremsdorf D: Hepatitis B virus HBx protein impairs liver regeneration through enhanced expression of IL- 6 in transgenic mice. J Hepatol 2013, 59(2):285-291.

13. Blindenbacher A, Wang $X$, Langer I, Savino R, Terracciano L, Heim MH: Interleukin 6 is important for survival after partial hepatectomy in mice. Hepatology 2003, 38(3):674-682.

14. Jin X, Zhang Z, Beer-Stolz D, Zimmers TA, Koniaris LG: Interleukin-6 inhibits oxidative injury and necrosis after extreme liver resection. Hepatology 2007, 46(3):802-812

15. Diehl AM: Cytokine regulation of liver injury and repair. Immunol Rev 2000, 174:160-171.

16. Hong F, Kim WH, Tian Z, Jaruga B, Ishac E, Shen X, Gao B: Elevated interleukin- 6 during ethanol consumption acts as a potential endogenous protective cytokine against ethanol-induced apoptosis in the liver: involvement of $\mathrm{BCl}-2$ and $\mathrm{BCl}-\mathrm{x}(\mathrm{L})$ proteins. Oncogene 2002, 21:32-43.

17. Hong F, Radaeva S, Pan H, Tian Z, Veech R, Gao B: Interleukin-6 treatment alleviates steatosis and ischemia/reperfusion injury in mice with fatty liver disease. Hepatology 2004, 40:933-941.

18. Sun Z, Klein AS, Radaeva S, Hong F, El-Assal O, Pan H, Batkai S, Tian Z, Hoshino S, Kunos G, Diehl A, Gao B: In vitro interleukin-6 treatment prevents mortality associated with fatty liver transplants in rats. Gastroenterology 2003, 125:202-215

19. Zhang X, Tachibana S, Wang H, Hisada M, Williams GM, Gao B, Sun Z Interleukin-6 is an important mediator for mitochondrial DNA repair after alcoholic liver injury in mice. Hepatology 2010, 52(6):2137-2147.

20. Bienvenu F, Gascan H, Coqueret O: Cyclin D1 represses STAT3 activation through a Cdk4-independent mechanism. J Biol Chem 2001, 276:16840-16847.

21. Flørenes VA, Lu C, Bhattacharya N, Rak J, Sheehan C, Slingerland JM, Kerbel RS: Interleukin- 6 dependent induction of the cyclin dependent kinase inhibitor p21WAF1/CIP1 is lost during progression of human malignant melanoma. Oncogene 1999, 18(4):1023-1032.

22. Moran DM, Mattocks MA, Cahill PA, Koniaris LG, McKillop IH: Interleukin-6 mediates $G(0) / G(1)$ growth arrest in hepatocellular carcinoma through a STAT 3-dependent pathway. J Surg Res 2008, 147(1):23-33.

23. Sinibaldi D, Wharton W, Turkson J, Bowman T, Pledger WJ, Jove R: Induction of p21WAF1/CIP1 and cyclin D1 expression by the Src oncoprotein in mouse fibroblasts: role of activated STAT3 signaling. Oncogene 2000, 19:5419-5427.

24. Selzner M, Clavien P-A: Failure of regeneration of the steatotic rat liver: disruption at two different levels of the regeneration pathway. Hepatology 2000, 31:35-42.

25. Torbenson M, Yang SQ, Liu HZ, Huang J, Gage W, Diehl AM: STAT-3 overexpression and p21 up-regulation accompany impaired regeneration of fatty livers. Am J Pathol 2002, 161(1):155-161.

26. Efferth T, Fabry U, Osieka R: Interleukin-6 affects melphalan-induced DNA damage and repair in human multiple myeloma cells. Anticancer Res 2002, 22(1A):231-234.

27. Bornholdt J, Dybdahl M, Vogel U, Hansen M, Loft S, Wallin H: Inhalation of ozone induces DNA strand breaks and inflammation in mice. Mutat Res 2002, 520(1-2):63-71.

28. Nagakawa Y, Williams GM, Zheng Q, Tsuchida A, Aoki T, Montgomery RA, Klein AS, Sun Z: Oxidative mitochondrial DNA damage and deletion in 
hepatocytes of rejecting liver allografts in rats: role of TNF-alpha. Hepatology 2005, 42(1):208-215.

29. Rodier F, Coppé JP, Patil CK, Hoeijmakers WA, Muñoz DP, Raza SR, Freund A, Campeau E, Davalos AR, Campisi J: Persistent DNA damage signaling triggers senescence-associated inflammatory cytokine secretion. Nat Cell Biol 2009, 11(8):973-979.

30. Sun Z, Zhang X, Locke JE, Zheng Q, Tachibana S, Diehl AM, Williams GM: Recruitment of host progenitor cells in rat liver transplants. Hepatology 2009, 49(2):587-597.

doi:10.1186/2045-3701-4-6

Cite this article as: Tachibana et al.: Interleukin- 6 is required for cell cycle arrest and activation of DNA repair enzymes after partial hepatectomy in mice. Cell \& Bioscience 2014 4:6.

\section{Submit your next manuscript to BioMed Central and take full advantage of:}

- Convenient online submission

- Thorough peer review

- No space constraints or color figure charges

- Immediate publication on acceptance

- Inclusion in PubMed, CAS, Scopus and Google Scholar

- Research which is freely available for redistribution 